DOI dx.doi.org/10.24866/7444-4707-6/142-153

\author{
М.Л. Бурдуковский, П.А. Перепелкина, И.В. Киселева
}

\title{
ДИНАМИКА РАСТИТЕЛЬНОСТИ И СВОЙСТВ ЛУГОВО-БУРЫХ ОПОДЗОЛЕННЫХ ПОЧВ В ХОДЕ ПОСТАГРОГЕННОГО РАЗВИТИЯ
}

Россия занимает первое место в мире по наличию земельных ресурсов и обладает $9 \%$ сельскохозяйственных угодий мира. В 50-60е г прошлого столетия на территории страны происходило активное освоение целинных и залежных территорий. Только в период с 1954 по 1959 гг в хозяйственный оборот было вовлечено около 42 млн га новых земель [Mелихов, 2014]. Развитие сельскохозяйственного производства на современном этапе развития страны находится в проблемном состоянии.

В результате экономического кризиса в 1990-х годах большие площади пахотных земель начали выводить из сельскохозяйственного оборота. Общая площадь заброшенных земель в 1990-2005 гг. составляет 30-40 млн га [Ушачев, 2009]. По данным Кундиус [2015] в настоящее время в каждом субъекте РФ не распахивается и не используется в сельскохозяйственном производстве примерно 28,5\% площади пахотных угодий. На основной части этих площадей восстанавливаются природные экосистемы, что позволяет отнести залежные поля к классическим объектам для изучения хода экологических сукцессий [Buell et al., 1971].

Важным аспектом при изучении залежных земель является восстановление плодородия и выявление возможных путей постагрогенной эволюции почв. Бывшие агроценозы, трансформированные в постагрогенные фитоценозы, отличаются от естественных по растительной структуре и её флористическоум составу [Kalinina et.al., 2015]. Образование залежей сопровождается самопроизвольным зарастанием, начиная с сорной (пионерная стадия зарастания), затем луговой флорой. Растительность, а именно ее видовой состав, ценотические группы, количественное и качественное соотношение видов, а также видовая насыщенность - является интегральным показателем демутационных процессов залежных земель [Работнов, 1995]. Зарастание должно привести к восстановлению исходного расти- 
тельного покрова и существенному изменению состояния старопахотных почв. Однако, в ходе восстановительной сукцессии, залежи могут являться рассадниками и резерватами сорной растительности и болезней растений, вследствие чего могут представлять серьезную угрозу для близлежащих пахотных угодий [Гордеев, Романенко, 2008], что необходимо учитывать при ведении сельскохозяйственной практики.

Зарастание бывших сельскохозяйственных угодий сопровождается изменением основных физических, химических и биологических свойств почвы, при этом трансформация в значительной степени затрагивает бывший пахотный горизонт [Скворцова и др., 1987; Falkengren-Grerup et al., 2006]. Направленность и величина изменений зависят от многих факторов (типов и свойств почв, истории предыдущего землепользования, биоклиматических условий региона) и могут сильно различаться, что объясняет интерес научной сферы к проблеме эволюции постагрогенных экосистем.

В Приморском крае начиная с 2013 г. реализуется Государственная программа развития сельского хозяйства, одним из пунктов которой является «Ввод в оборот неиспользуемой пашни и залежных земель сельскохозяйственного назначения» [Государственная программа «Развитие сельского хозяйства... от 07.12.2012 г ]. Между тем вопросы трансформации залежных почв территории Дальневосточного региона остаются малоизученными.

Цель исследования - изучение структуры растительных сообществ и некоторых агрохимических свойств почв в ходе постагрогенной трансформации залежных экосистем юга Приморского края.

Исследования проводили на бывших пахотных землях Уссурийского городского округа Приморского края (Табл.1). Изученные участки представляли собой залежи 15, 20, и 35-летнего возраста. В 1970-1980 гг. исследуемые поля использовались под полевые и овощные севообороты. В эти же годы была проведена последняя агрохимическая съемка территорий совхозов. Для сравнения привлечены образцы ненарушенной почвы, расположенной в непосредственной близости от залежей и развивающиеся под зональным типом растительности, и с пахотной почвы с поля, используемого под возделывание сои (контрольный вариант длительного опыта по использованию удобрений на территории ФНЦ агробиотехнологий Дальнего Востока им. А.К. Чайки). 
Характеристика объектов исследований

\begin{tabular}{|l|l|l|l|}
\hline \multirow{2}{*}{$\begin{array}{c}\text { Возраст } \\
\text { залежи, лет }\end{array}$} & \multicolumn{2}{|c|}{$\begin{array}{c}\text { Географические координаты, } \\
\text { град. }\end{array}$} & \multirow{2}{*}{$\begin{array}{c}\text { Тип доминирующей } \\
\text { синузии }\end{array}$} \\
\cline { 2 - 3 } & широта N & долгота E & \\
\hline $0^{*}$ & 43.859189 & 131.945269 & посевы сои \\
\hline 15 & 43.837730 & 132.093442 & злаково-полынная \\
\hline 20 & 43.751206 & 132.020417 & $\begin{array}{l}\text { 3лаково-полынно- } \\
\text { разнотравная }\end{array}$ \\
\hline 35 & 43.842654 & 131.917306 & осоково-злаковая \\
\hline
\end{tabular}

Примечание: пашня

Почва на исследуемых участках - лугово-бурая оподзоленная (Gleyic Cambisols). Лугово-бурые почвы имеют морфологические и физикохимические признаки и свойства, близкие как к луговым, так и к бурым лесным почвам. Для них характерна высокая степень гумусированности и дренированности, тяжелый гранулометрический состав. Залегают эти почвы на озерно-аллювиальных отложениях тяжелого гранулометрического состава и формируются под остепненными разнотравно-злаковыми группировками растительности в комплексе с кустарниковыми зарослями. Распространены в основном в пределах Западно-Приморской равнины, а также на территории Среднеамурской равнины в нижнем течении р. Уссури. Эти почвы составляют основной пахотный фонд (в комплексе с луговыми глеевыми) в Приморском крае, где они большей частью приурочены ко второй и третьей надпойменным террасам оз. Ханка на высоте 80-150 м над ур. м. В центральных земледельческих районах Приморья они занимают более 50\% сельскохозяйственных угодий [Иванов, 1976; Синельников, 1987].

Почва залежей 15, 20-летнего возраста имели следующий набор генетических горизонтов: AU (0-10 см) - темно-серый, легкосуглинистый, крупнозернистой структуры, задернован, постепенно переходящий в более плотный горизонт Elnng (10-30 см) - коричнево-серый, легкосуглинистый, плотный, с большим количеством железо-марганцевых конкреций (далее - конкреции), с заметным переходом в BELg (30-40 см) - серый, плотный, среднесуглинистый, встречаются конкреции, глыбистокомковатый с постепенным переходом в горизонт ВТg (40-70 см) - плотный, серо-бурого цвета, глинистый и горизонт Cg (70-90 см) - представляет собой плотную глину. 
Почва залежи 35-летнего возраста сформирована в условиях постоянного или длительного переувлажнения. Профиль почвы имеет следующий набор генетических горизонтов: AU (0-12 см) - темно-серый, рыхлый, зернистой структуры, сильно задернован, постепенно переходящий в горизонт Elnng (12-22 см) - светло-серый, встречаются конкреции, супесчаный, с резким переходом в ВТg (22-55 см) - серо-коричневый, свежий, плотный, легкосуглинистый, комковато-глыбистый, постепенно переходит в горизонт Cg (55-90 см) - сизовато-серый, плотный, среднесуглинистый, комковатой структуры.

Отбор проб проводили из верхних слоёв профиля и трёх прикопок на глубинах 0-20 и 20-30 см. В смешанных образцах определяли кислотность почв ( $\mathrm{pH}$ солевой вытяжки) на $\mathrm{pH}$-метре Mettler Toledo S220-Kit (Швейцария), содержание гумуса методом Тюрина, поглощённые основания - по Шолленбергеру, подвижные формы фосфора и калия - по Кирсанову [Аринушкина, 1970].

Для изучения растительных сообществ применялись стандартные геоботанические методы [Раменский, 1971], для определения возраста деревьев и подроста - методы дендрохронологии [Шиятов и др., 2000].

Климат в Приморском крае муссонный, с малоснежной зимой и влажно-тропической погодой летом, что способствует активному разложению поступающих в почву растительных остатков [Иванов, 1976]. Для почв района исследований атмосферные осадки являются основным источником поступления влаги. Годовое их количество в среднем составляет 500-900 мм. Осенне-летний период территория Приморского края характеризуется частым прохождением тайфунов, которые зарождаются над Тихим океаном. В это время (июль-сентябрь) на обширной территории выпадают дожди циклонического типа. В зимний период погоду определяет прохождение сухих холодных воздушных масс, формирующихся в области азиатского антициклона.

При обработке данных использовали общепринятые статистические методы с использованием программы Statistica v.13.

Возобновление растительного покрова на залежных полях зависит от экотопических условий, и, в первую очередь, от фитоценотического окружения и режима увлажнения. Первое обуславливает поступление определенного набора семян, а второе их успешную приживаемость. Согласно ли- 
тературным данным, формирование растительного покрова на залежах проходит по определенной схеме и включает несколько стадий [Работнов, 1995]. Из них можно выделить основные: 1) зарастание однолетними сорняками, которые обычно растут в посевах культурных растений; 2) олуговение - увеличение, а затем господство полыней и бобовых; с течением времени на залежах активно развиваются злаковые, которые могут занимать значительные площади сплошными зарослями; 3) залесение - восстановление подроста древесных растений. При обследовании полей выведенных из сельскохозяйственного оборота нами выделено несколько типов естественного зарастания в зависимости от возраста залежей и сформированных условий экотопа. Все они относятся ко второй и третьей стадиям.

Наиболее устойчивыми доминантами в залежных экосистемах юга Приморского края являются вейниково-злаковые и полынные синузии. На залежах 15 и 20-летнего возраста доминирующим семейством является Asteraceae, существенно участие семейства Fabaceae. На 35-летних залежах высокое участие в травостое семейства Роасеае. Максимальным видовым разнообразием характеризуются средневозрастные залежи с возобновлением древесных растений. С увеличением возраста залежи видовое разнообразие снижается.

Согласно анализу семейственных спектров, с увеличением возраста залежи происходит увеличение разнообразия семейств (Рис. 1), что согласуется с данными полученными другими исследователями на территории Приморского края [Комаров, 1917; Шишкин, 1927; Колесников, 1955]. Наименьшее разнообразие характерно для средневозрастных 15-ти летних залежей. Возобновление древесных растений происходит очень медленно. Согласно проанализированным древесным кернам, успешное закрепление единичных особей подроста происходит спустя 10 лет после вывода поля из сельскохозяйственного оборота. В большинстве случаев пионерами становятся представители рода Salix. Появление представителя коренных лесов, подроста Q. mongolica Fisch. ex Turcz., происходит в возрасте 15-20 лет и приурочено к периферии залежи, граничащей с лесным массивом.

Возобновление древесных происходит очень медленно. Согласно проанализированным древесным кернам, успешное закрепление единичных особей подроста происходит спустя 8-10 лет после вывода поля из сельскохозяйственного оборота. В большинстве случаев пионерами становятся представители рода Salix. Распространение семян ветром на далекие рассто- 
яния и сохранение всхожести даже в условиях избыточного переувлажнения на продолжении нескольких лет способствует закреплению их в фитоценозе. Высокая толерантность подроста ивы к условиям среды помогает переносить затопление территорий и проходящие многочисленные пожары.

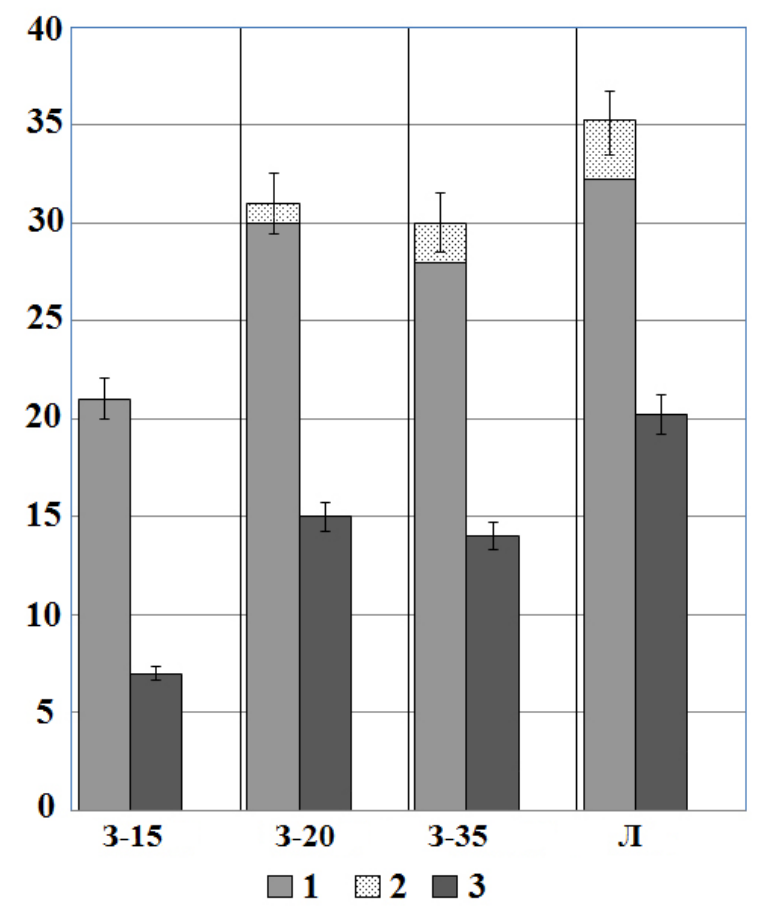

Puc. 1. Усредненное количество видов и семейств растений на разновозрастных залежах и в коренном лесу (в шт.).

3-15 - залежи 15-летнего возраста, 3-20 - залежи 20-летнего возраста, 3-35 - залежи 35-летнего возраста, Л - лес.

1 - Виды растений, 2 - Древесные, 3- Семейства, $\mathrm{P} \leq 0,05 \%$.

Все образцы древесных кернов представителей этого рода имеют следы повреждения пожарами в разном возрасте. В условиях стабильного гидрологического режима и отсутствия пожаров появляется подрост Betula platyphylla, Populus tremula. Несмотря на то, что в ближайшем окружении эти виды деревьев могут и не присутствовать, при сильных ветрах их семена могут уноситься ветром до 2 км и более [Верхунов, 1979]. Спустя 15-20 лет после вывода поля из севооборота, в условиях незначительной пирогенной нагрузки появляется подрост Quercus mongolica - эдификатор аборигенных лесных сообществ, но его распространение ограничено по территории поля. Однако, большинство исследуемых залежей подвержены пожарам и медленно растущий подрост дуба на них просто сгорает. Мелкий подрост Populus maximowiczii встречается на залежах разного режима увлажнения. 
В условиях частого воздействия пирогенного фактора на растительные сообщества возобновление древесных сильно затруднено. Растительные сообщества начинают развиваться практически с нуля или же сильно тормозят в развитии. На протяжении длительного времени после пожара на полях преобладают различные виды полыни, а видовое разнообразие снижается. Схожая ситуация в Приамурье была описана в работах С.Д. Шлотгауэр [Шлотгауэр, 2007, 2008].

Результат анализа взаимоотношений агрохимических свойств почв и типа растительности показал их высокую корреляцию. Гумусовый горизонт наиболее зависим от типа растительного сообщества [Falkengren-Grerup, 2006]. Самыми высокими показателями содержания гумуса (рис. 2) характеризуются аборигенный лесной массив и 35-летняя залежь. Увеличение содержания гумуса в поверхностном которой во многом связано со значительным привносом органического вещества с корневой массой растений.

В изученных лугово-бурых почвах, находящихся в залежи более 20 лет отмечено разделение исходного пахотного горизонта на подгоризонты, как по морфологическим свойствам, так и по содержанию органического вещества. Разница в содержании гумуса между верхним (0-10 см) и нижележащим горизонтом составляет 1-2 \%. Согласно оценочным показателям [Орлов, Бирюкова, Розанова, 2004], содержание гумуса в изученных залежах находится на уровне «низких» и «ниже средних» значений, и составляет в среднем от 3,1 до 5,5\%.

Под воздействием травянистой растительности верхняя часть бывшего пахотного горизонта преобразуется в дерновый горизонт. Наибольшее проявление этого процесса отмечено зрелых залежах. В сформировавшемся горизонте присутствует большое количество органического вещества, содержание углерода при этом составляет порядка $5 \%$, что в пересчете на гумус характеризуется как «высокое» содержание (8\%).

Согласно различным литературным источникам [Хавкина, 2004; Пуртова, Бурдуковский, 2016; Пуртова, Костенков, Щапова, 2017] для пахотных лугово-бурых оподзоленных почв района исследований содержание гумуса варьируется от 3,3 до 4,3 \%. Исходя из этих данных, при оставлении изученных почв в залежном состоянии на срок менее чем 15 лет, содержание гумуса в них остается на уровне фонового содержания. В более зрелых залежах можно отметить увеличение содержания гумуса. Кроме того, ориентируясь на архивные данные по конкретным полям, за 
20-летний период нахождения участка в залежном состоянии, содержание гумуса в почве увеличилось на 1,8 \% (с 3,7 до 5,5 \%). Это связано с прекращением выноса органического вещества с урожаем и накоплением его в пределах почвенного профиля.
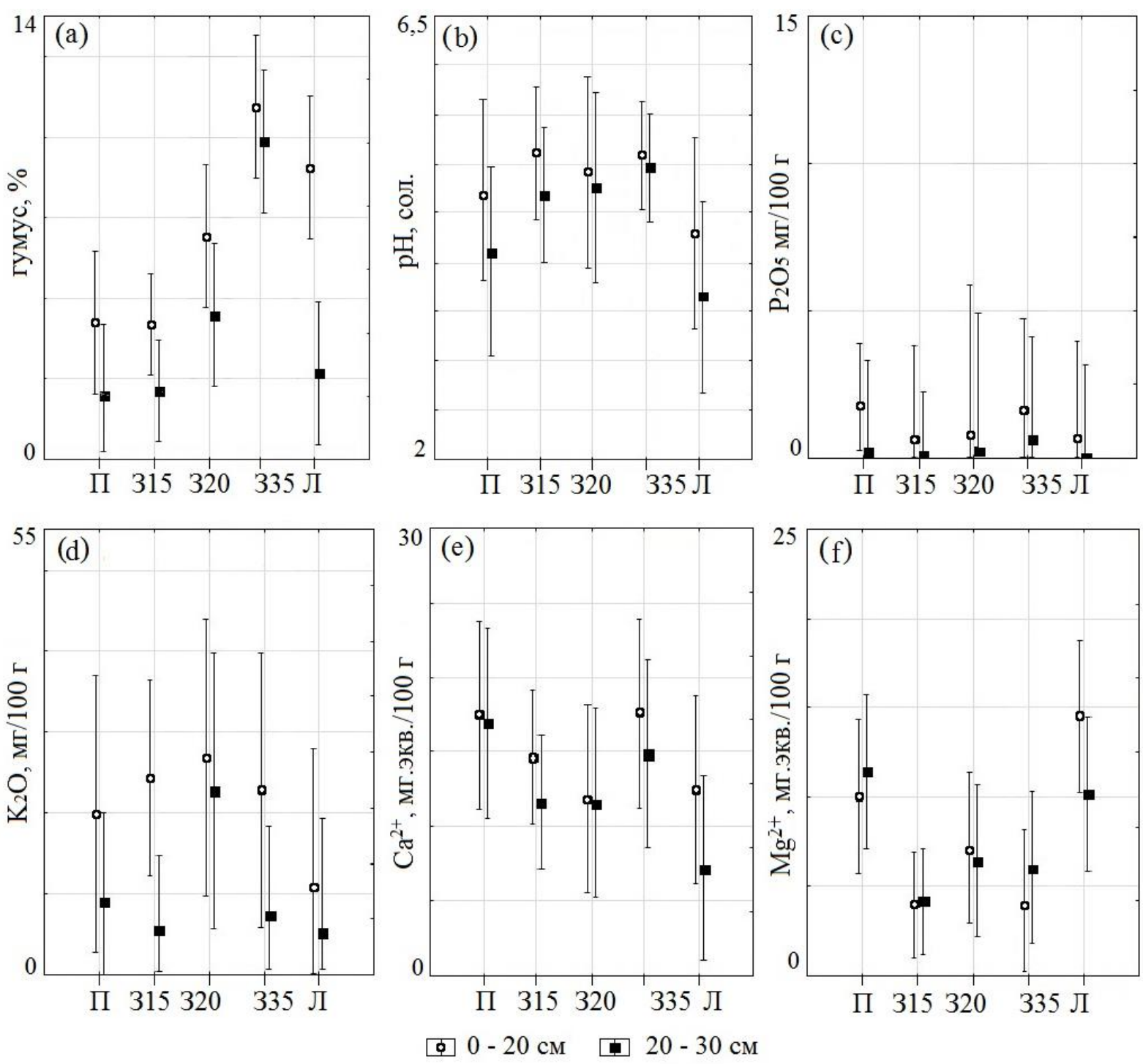

Puc. 2. Агрохимические свойства лугово-бурой оподзоленной почвы при различном хозяйственном использовании, ANOVA, Tukey тест, $\mathrm{P}<0,05)$

Многие исследователи гумусного состояния различных типов почв, находящихся в залежи, подтверждают, что по мере увеличения срока снятия антропогенной нагрузки статус гумусированности почв повышается [Степанов, Суханова, 2007; Суханова и др., 2007; Poulton, Pye, Hargreaves, 2003; Post, Kwon, 2000; Романовская, Аракелян, 2007; Wright, Dou, Hons, 2007; Zhang, Penc, 2006]. 
Все исследуемые почвы по уровню кислотности относятся к слабокислым. На этапе активного возобновления древесных видов растений на залежах, кислотность почв увеличивается и уменьшается содержание подвижных форм калия. Прекращение сельскохозяйственного использования привело к снижению содержания катионов $\mathrm{Ca}^{2+}$ и $\mathrm{Mg}^{2+}$ и подвижных форм фосфора. Увеличение катионов $\mathrm{Ca}^{2+}$ отмечено в почве 35 -летней залежи. Аналогичные закономерности отмечены для дерново-подзолистых почв, но увеличение содержание катионов происходило в них на более ранних сроках после начала залежного процесса [Литвинович и др., 2009]. Низкое содержание подвижных форм фосфора в исследуемых почвах обусловлено региональными особенностями почвообразования, а именно, процессом конкрециобразования [Timofeeva et. al., 2014], в результате которого фосфор переходит в недоступное фиксированное состояние в железомарганцевые конкреции. На более поздних сроках после начала залежного процесса нами отмечено увеличение содержание подвижных форм фосфора.

Вероятно, подобная картина является закономерным этапом развития залежных лугово-бурых оподзоленных почв Приморского края и отражает изменения агрохимических свойств, которые происходят при прекращении или снижении уровня антропогенного воздействия.

\section{Литература}

1. Аринушкина Е.В. Руководство по химическому анализу почв. М.: МГУ, 1970. $487 \mathrm{c}$.

2. Верхунов П.М. Прирост запаса разновозрастных сосняков. Новосибирск: Наука, 1979. 254 с.

3. Гордеев А.В., Романенко Г.А. Проблемы деградации и восстановления продуктивности земель сельскохозяйственного назначения в России. М.: Росинформагротех, 2008. 69 с.

4. Государственная программа «Развитие сельского хозяйства и регулирования рынков сельскохозяйственной продукции, сырья и продовольствия. Повышение уровня жизни сельского населения Приморского края» на 2013-2020 годы от 07.12.2012 г. [Электрон. pecypc]. URL: http://www.agrodv.ru/content/programmy-razvitiya-apk

5. Иванов Г.И. Почвообразование на юге Дальнего Востока. М.: Наука, 1976. 200 с. 
6. Колесников Б.П., Гутникова 3.И. Растительность залежей Приханкайской равнины // Сообщения ДВФ АН СССР. 1955. Вып. 7. С. 10-15, 22-38.

7. Комаров В.Л. Типы растительности Южно-Уссурийского края // Труды почвенно-ботанических экспедиций по исследованию колонизационных районов Азиатской России. Часть II. Ботанические исследования 1913 г. Вып. 2. Петроград, 1917. 296 с.

8. Кундиус В.А., Воронкова О.Ю. Эколого-экономические предпосылки использования залежных земель Алтайского края в направлении производства органической продукции // Вестник алтайской науки. 2015. №3. С. 295-302.

9. Литвинович А.В., Дричко В.Ф., Павлова О.Ю., Чернов Д.В., Шабанов М.В. Изменение кислотно-основных свойств окультуренных дерново-подзолистых почв легкого гранулометрического состава в процессе постагрогенной трансформации // Почвоведение. 2009. № 6. С. 680-686.

10. Мелихов В.В. Освоение целины - поворотный этап глобального развития сельскохозяйственного производства // Орошаемое земледелие. 2014. №3. С.3-4.

11. Орлов Д.С., Бирюкова О.Н, Розанова М.С. Дополнительные показатели гумусного состояния почв и их генетических горизонтов // Почвоведение. 2004. №8. С.918-926.

12. Пуртова Л.Н., Бурдуковский М.Л. 2016. К оценке экологического состояния лугово-бурых почв Приморья // Вестник КрасГАУ. №.7. С.12-18.

13. Пуртова Л.Н. , Костенков Н.М. , Щапова Л.Н. 2017. Оценка гумусного состояния и продуцирования СО2 почвами природных и агрогенных ландшафтов юга Дальнего Востока России // Почвоведение. 2017. №.1. C.48-55.

14. Работнов Т.А. История фитоценологии: Учебное пособие. М.: Аргус, 1995. 158 с.

15. Раменский Л. Г. Проблемы и методы изучения растительного покрова. Избранные работы. Л.: Наука, 1971. 610 с.

16. Романовская А. А., Аракелян Т. Г. Почвенный органический углерод залежных земель в Московской области // Труды IV Всероссийской конференции «Гуминовые вещества в биосфере». С-Пб: СПбГУ, 2007. C. 618-626. 
17. Синельников Э. П. Почвы земледельческой зоны юга Дальнего Востока. Уссурийск: ПГСХА, 1987. 216 с.

18. Скворцова Е.Б., Баранова О.Ю., Нумеров Г.Б. Изменение микростроения почв при зарастании пашни лесом // Почвоведение. 1987. № 9. C. 101-109.

19. Степанов А.А., Суханова Н.И. Изменение молекулярномассового распределения и степени амфифильности гуминовых веществ чернозема обыкновенного карбонатного в ходе естественного восстановления степной растительности // Труды IV Всероссийской конференции «Гуминовые вещества в биосфере». С-Пб: СПбГУ, 2007. С. 86-94.

20. Суханова Н.И., Курганова И.Н, Лопес де Гереню В.О., Керимзаде В.В. Изменение содержания органического углерода и дыхательной активности чернозема обыкновенного под влиянием зарастания естественной растительностью // Труды IV Всероссийской конференции «Гуминовые вещества в биосфере». С-Пб: СПбГУ, 2007. С. 310-314.

21. Ушачев И. Г. Роль аграрной науки в обеспечении продовольственной безопасности России. М. : Росинформагротех, 2009. 24 с.

22. Хавкина Н. В. Гумусообразование и трансформация органического вещества в условиях переменно-глеевого почвообразования: монография. Уссурийск: ПГСХА., 2004. 270 с.

23. Шишкин И.К. Сорная растительность посевов и процесс зарастания залежей в южном Приморье // Производительные силы Дальнего Востока. 1927. Т. 3. С. 213-229.

24. Шиятов С.Г., Ваганов Е.А., Кирдянов А.В., Круглов В.Б., Мазепа В.С, Наурзбаев М.М., Хантемиров Р.М. Методы дендрохронологии. Часть I. Основы дендрохронологии. Сбор и получение древесно-кольцевой информации. Красноярск: КрасГУ, 2000. 80 с.

25. Шлотгауэр С.Д. Трансформация видового разнообразия растительности Приамурья под влиянием пожаров // Сибирский экологический журнал. 2007. № 2. С. 251-255.

26. Шлотгауэр С.Д., Крюкова М.В. Воздействие пирогенного фактора на состояние растительного покрова в бассейне Амура // Вестник Дальневосточного отделения Российской академии наук. 2008. № 1. С. 59-68.

27. Buell M.F., Buell H.F., Small J.A., Siccama T.G. Invasion of Trees in Secondary Succession on the New Jersey Piedmont // Bulletin of the Torrey Botanical Club. 1971. V.98. P.67-74. 
28. Falkengren-Grerup U., ten Brink D.-J., Brunet J. Land use effects on soil $\mathrm{N}, \mathrm{P}, \mathrm{C}$ and $\mathrm{pH}$ persist over $40-80$ years of forest growth on agricultural soils // Forest Ecol. Manag. 2006. V.225. P. 74-81.

29. Kalinina O., Goryachkin S.V., Lyuri D.I., Giani L. Postagrogenic development of vegetation, soils and carbon stocks under self-restoration in different climatic zones of European Russia // Catena. 2015. V. 129. P. 18-29.

30. Post W.M., Kwon K.C. Soil carbon sequestration and land use change: processes and potential // Global Change Biology. 2000. V.6. P. 317-328.

31. Poulton P.R.; Pye E., Hargreaves p. R., Jenkinson D. S. Accumulation of carbon and nitrogen by old arable land reverting to Woodland // Global Change Biol.2003. V. 9. P. 942-955.

32. Timofeeva, Y.O., Karabtsov, A.A., Semal, V.A., Burdukovskii, M.L., Bondarchuk, N.V. Iron-manganese nodules in udepts: the dependence of the accumulation of trace elements on nodule size // Soil Science Society of America Journal. 2014. V.78. P. 767-778.

33. Wright A.L. Dou F., Hons F.M. Soil organic C and N distribution for wheat cropping systems after 20 years of conservation tillage in central Texas // Agriculture, Ecosystems and Environment. 2007. V.121. P. 376-382.

34. Zhang B., Penc X. Organic matter enrichment and aggregate stabilization in a severely degraded ultisol after reforestation // Pedosphere. 2006. V.16. P. 699-706. 